\title{
Preneoplastic foci in mice fed diethyl 1, 4-dihydro, 1, 4, 6-trimethyl 3, 5-pyridine decarboxylate are resistant to protoporphyrin accumulation
}

\author{
Samuel W. French ${ }^{1}$, M. Waheed Roomi² \\ ${ }^{1}$ Department of Pathology, Harbor UCLA Medical Center, Torrance, CA 90509, USA \\ ${ }^{2}$ Dr. Rath Research Institute, Santa Clara, CA 95050, USA
}

\section{Address for correspondence:}

Dr. Samuel W. French, Department of Pathology, Harbor UCLA Medical Center, Torrance, CA 90509, USA. E-mail: sfrench@labiomed.org Received: 01-02-2015, Accepted: 23-03-2015

It has been shown that preneoplastic liver cell foci and hepatic nodules generated by thioacetamide (TAA) in drug-primed mice, which were first fed diethyl 1, 4-dihydro, 1, 4, 6-trimethyl 3, 5-pyridine decarboxylate (DDC) or griseofulvin (GF) for 5 months were resistant to protoporphyrin accumulation. ${ }^{[1]}$ DDC or GF are potent porphyrinogenic drugs and accumulate protoporphyrin in the mouse liver. Although DDC or GF are withdrawn for 1 month, when treated with TAA, the nodules formed on the 5 th or 7 th day of treatment were devoid of protoporphyrin deposits. Feeding DDC or GF for 8 months induced liver tumors which were devoid of protoporphyrin deposits. In contrast, the surrounding liver tissue contained numerous protoporphyrin deposits. This could be attributed to the decreased activity of delta-aminolevulinate synthase, the first rate-limiting enzyme in protoporphyrin synthesis. Furthermore, there could be an increased activity of ferrochelatase, which catalyzes the incorporation of iron into protoporphyrin, and increased activity of heme oxygenase, the last enzyme in porphyrin degradation. Protoporphyrin deposits were found in the normal liver parenchyma, but not in the hyperplastic nodules (HNs) or hepatocellular carcinomas formed in mice fed GF or DDC for 5-12 months. ${ }^{[2-4]}$ C3H male mice, aged 4 weeks (Harlan, Sprague-Dawley, San Diego, CA, USA), were fed a protein-rich $25 \%$ semisynthetic

\begin{tabular}{|l|c|}
\hline \multicolumn{2}{|c|}{ Access this article online } \\
\hline \multirow{2}{*}{ Website: } & Quick Response Code \\
http://www.hrjournal.net/ & \\
\hline & DOI: \\
10.4103/2394-5079.155984 & \\
&
\end{tabular}

complete standard Tekland test diet ad libitum (Tekland, Madison, WI, USA) with $0.1 \%$ DDC or $2.5 \%$ GF for 1 year and then sacrificed. Control mice were fed the basal diet without DDC. As soon as the mice were killed, their liver was removed. Portions of the liver were fixed in formalin and embedded in paraffin for light microscopic analysis by hematoxylin-eosin and gamma glutamyl transpeptidase (GGT) was accessed by histochemistry. Figure 1 illustrates an $\mathrm{HN}$ from a mouse fed DDC for 1 year. The tumor is devoid of protoporphyrin and is surrounded by normal liver parenchyma filled with protoporphyrin deposits. Figure 2 shows hyperplastic foci stained red for GGT, a marker for HN, showing that the precursor lesion is devoid of protoporphyrin deposits. HN or foci are generated during the process of liver cancer development in response to chemical carcinogens or dietary

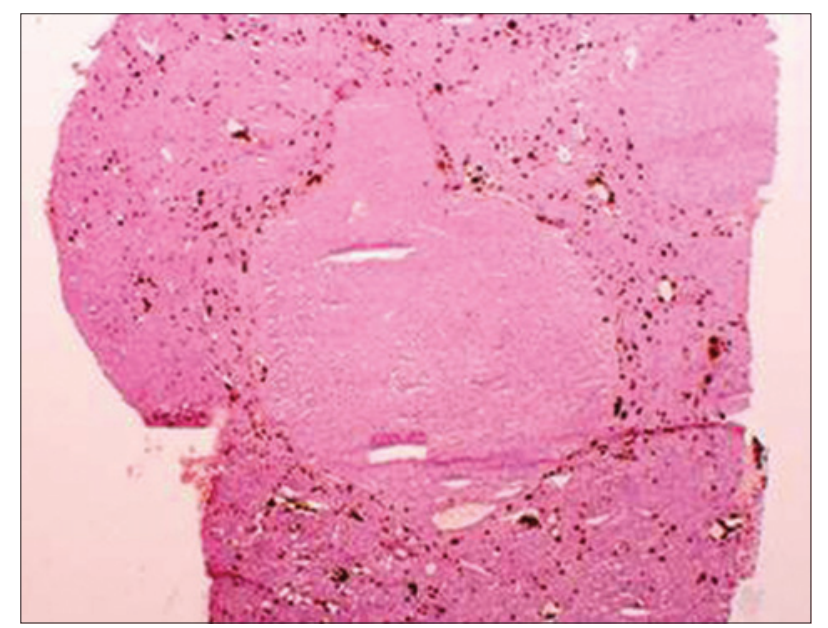

Figure 1: Liver from a mouse fed diethyl 1, 4-dihydro, 1, 4, 6-trimethyl 3, 5-pyridine decarboxylate for 1 year $(\times 57)$. Note the hyperplastic nodule is devoid of brown protoporphyrin pigment, whereas the surrounding normal liver parenchyma is filled with protoporphyrin deposits 


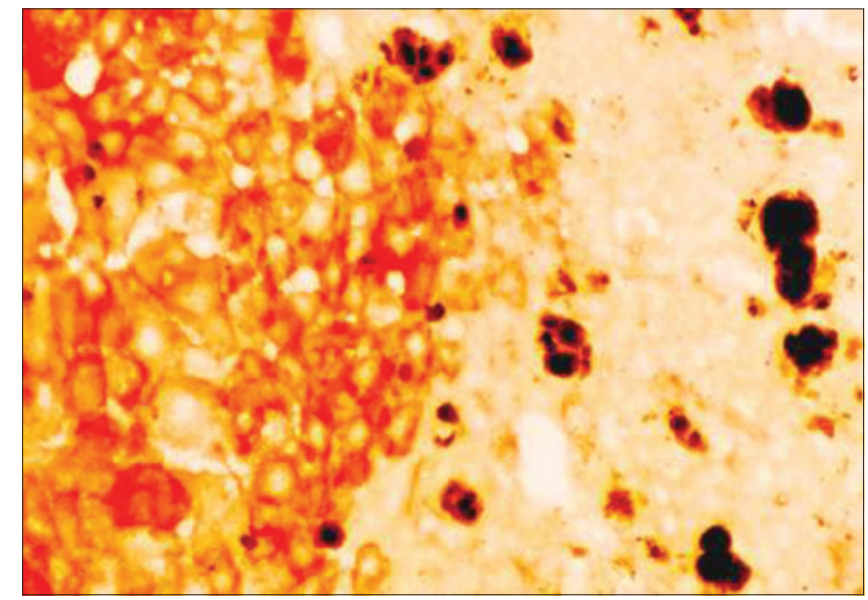

Figure 2: Liver from a mouse fed diethyl 1, 4-dihydro, 1, 4, 6-trimethyl 3, 5-pyridine decarboxylate (DDC) for 5 months, then withdrawn from DDC for 1 month, then refed DDC for 3 days $(\times 567)$. Note that the hyperplastic nodule stained red for gamma-glutamyl transferase is devoid of protoporphyrin pigment whereas the normal liver parenchyma has numerous protoporphyrin deposits as shown

manipulations. HN is a population of cells from which hepatocelluar carcinoma can develop. The HN studied here resembles resistant phenotypes which grow in an otherwise toxic environment of potent porphyrinogenic drugs DDC and GF. The HN is resistant to protoporphyrin accumulation whereas the surrounding normal liver is filled with protoporphyrin. This observation is further supported by the fact that HNs generated by diethylnitrosamine initiation and various promoting regimens are resistant to their own promoting agents. For example, the nodules produced by resistance to a cytotoxicity model using 2-acetyl aminofluorene (2-AAF) are resistant to 2-AAF metabolism. ${ }^{\text {.5] }}$ The nodules produced by choline methionine deficient diet are resistant to fat accumulation. ${ }^{[6]}$ The $\mathrm{HN}$ nodules generated in orotic acid models are resistant to imbalances of nucleotide pools created by orotic acid $;{ }^{[7]}$ nodules generated in lasiocarpine model are resistant to megalocytic effect of Senecio alkaloid. ${ }^{[8]}$ These selective resistances to cytotoxicity models appear to be precursor lesions for hepatocellular carcinoma development.

\section{REFERENCES}

1. Roomi MW, Gaal K, Yuan QX, French BA, Fu P, Bardag-Gorce F, French SW. Preneoplastic liver cell foci expansion induced by thioacetamide toxicity in drug-primed mice. Exp Mol Pathol 2006;81:8-14.

2. Tazawa J, Irie T, French SW. Mallory body formation runs parallel to gamma-glutamyl transferase induction in hepatocytes of griseofulvin-fed mice. Hepatology 1983;3:989-1001.

3. Oliva J, Bardag-Gorce F, French BA, Li J, McPhaul L, Amidi F, Dedes J, Habibi A, Nguyen S, French SW. Fat10 is an epigenetic marker for liver preneoplasia in a drug-primed mouse model of tumorigenesis. Exp Mol Pathol 2008;84:102-12.

4. Nagao Y, Wan YJ, Yuan QX, Kachi K, Marceau N, French SW. Mouse model of hepatocellular hyperplastic nodule formation characterization of mRNA expression. Hepatol Res 1999;15:110-23.

5. Solt DB, Medline A, Farber E. Rapid emergence of carcinogen-induced hyperplastic lesions in a new model for the sequential analysis of liver carcinogenesis. Am J Pathol 1977;88:595-618.

6. Shinozuka H, Sells MA, Katyal SL, Sell S, Lombardi B. Effects of a choline-devoid diet on the emergence of gamma-glutamyltranspeptidasepositive foci in the liver of carcinogen-treated rats. Cancer Res 1979;39:2515-21.

7. Rao PM, Nagamine Y, Roomi MW, Rajalakshmi S, Sarma DS. Orotic acid, a new promoter for experimental liver carcinogenesis. Toxicol Pathol 1984;12:173-8.

8. Hayes MA, Roberts E, Farber E. Initiation and selection of resistant hepatocyte nodules in rats given the pyrrolizidine alkaloids lasiocarpine and senecionine. Cancer Res 1985;45:3726-34.

How to cite this article: French SW, Roomi MW. Preneoplastic foci in mice fed diethyl 1, 4-dihydro, 1, 4, 6-trimethyl 3, 5-pyridine decarboxylate are resistant to protoporphyrin accumulation. Hepatoma Res 2015;1:50-1.

Source of Support: Nil. Conflict of Interest: None declared. 